DOI 10.15826/qr.2015.2.105

УДК 256+2-172.2+2-136.7

Такако Ямада

«ИСТОЧНИК ДОБРЫХ СИЛ НАХОДИТСЯ НА ВОСТОКЕ...": ПРЕДСТАВЛЕНИЯ ШАМАНОВ СОВРЕМЕННОЙ ЯКУТИИ (САХА) О ВСЕЛЕННОЙ, БОЖЕСТВАХ И ДУХАХ

Takako Yamada

\title{
“THE SOURCE OF GOOD FORCES IS LOCATED IN THE EAST...”: YAKUT (SAKHA) SHAMANS' CONCEPTS ABOUT THE UNIVERSE AND SPIRITUAL BEINGS
}

This paper deals with the concept of the universe and belief in spiritual beings among contemporary Sakha (Yakut) shamans. It is based on field data collected in 1994 among several shamans of the Sakha Republic (Yakutia). Since Soviet atheistic policy prohibited shamanic traditions, the idea of the universe and spiritual beings varies depending on the shaman's own interpretations based on his or her own supernatural experiences. The paper argues that the concepts of spiritual beings reintegrated into a new worldview, and that animistic beliefs can be formed by an interpretation of individual experiences. This also suggests that the belief in spiritual beings is closely related to a shaman's tradition and influences its forms.

Keywords: Yakut religious traditions, shamanism, Yakut cosmogony, shamanic rituals, animism.

В работе рассматриваются представления современных якутских шаманов о вселенной и духах, главным образом по материалам полевых исследований в Республике Саха (Якутия) в 1994 г. Основной метод исследования - сбор интервью среди носителей шаманской традиции. Так как шаманские ритуалы долгое время были запрещены в СССР, произошло частичное разрушение целостной концепции мироустройства. Представления о вселенной и духах у каждого отдельного шамана отличны от других и основываются на личном сверхъестественном опыте. На основе проведенных исследований сделан вывод о том, что анимистические представления могут быть сформированы исходя из индивидуального опыта и миропонимания отдельного человека, а вера в духов тесно связанная с шаманской традицией, влияет на формы ее воплощения.

Ключевые слова: религиозные традиции якутов, шаманизм, якутская космогония, шаманские ритуалы, анимизм. 


\section{Prologue}

It was from July to August 1994 that I first visited the Republic of Sakha (Yakutia). Before that time, I never imagined I would be in Siberia as an anthropologist, since Siberia was an area so distant for us Japanese anthropologists due to the communist regime of the Soviet Russia. However, in 1994 I had a good opportunity to make a field trip to Yakutia. It was due to an encounter with Sakha ethnologists at the International Conferences on Shamanism, in Seoul in 1991 and again in Budapest in 1993, where they invited me to visit Yakutia.

I had been interested in shamanism as a field of anthropology since my several field trip to Ladakh in Western Tibet, India in the 1980's. The Ladakhi had maintained their own culture and a worldview which included shamanic tradition, even though their way of life was changing little by little in face of contemporary circumstances. In contrast with the Ladakhi, the Sakha were compelled under the anti-religious policy of the Soviet Russia to give up their religious tradition. Had they completely abandoned their own traditional culture? Sakha ethnologist whom I met during the conferences vividly reported the revival of shamanism among the Sakha. I took a great interest in their modern cultural situations, worldview and shamanic tradition, and I accepted my Sakha friends' invitation.

I was not the first anthropologist in the West who took an interest on the revival of shamanism among the Sakha after the collapse of the Soviet Russia. A bit earlier than me, Dr. M. Balzer did her first trip to Yakutia, after her work among the Khanty, in 1986 and several trips from 1991-95. She was more interested in the kind of political aspects of the revitalization of shamanism [Balzer, 1993; Balzer, 1996]. In contrast, I was firstly more curious about their cosmology and animistic way of thinking, which this article describes.

I have not visited Yakutia since my last field trip in 2001, but I have noticed that shamanistic aspects of Sakha culture is attracting ethnologists and anthropologists even today. Zola examined the revival of shamanism among the Sakha with references to the contemporary art [Zola], while. Rozwadowski analyzes the shamanic themes in rock art in the Sakha Republic. The presentation was cancelled, but Vasilieva and Kośko were to give a paper on "Sakha shamans in the past and in the present" during the 10the conference of the International Society for Shamanistic Research held at Warsaw on 5-9 October 2011 [Program and Abstracts]. Zola and Rozwadovski published their full papers later [Zola; Rozwadowski].

Although I made this article published in 1997 [Yamada, 1997], basing on my first field trip to Yakutia in 1994, I do hope this will contribute to the understanding of shamanistic and animistic aspects of Sakha culture. 


\section{Пролог}

Моя первая поездка в Республику Саха (Якутия) состоялась в июле - августе 1994 г. До этого времени я даже не допускала самой возможности проведения полевых исследований в Сибири. Для нас, японских антропологов, она представлялась далекой и недоступной в условиях доминирования коммунистической системы в Советской России. И все-таки у меня появилась возможность отправиться в экспедицию в Якутию. Произошло это благодаря знакомству во время международных конференций по шаманизму в Сеуле (1991) и Будапеште (1993) с этнологами из Республики Саха (Якутия), которые и пригласили меня посетить Якутию.

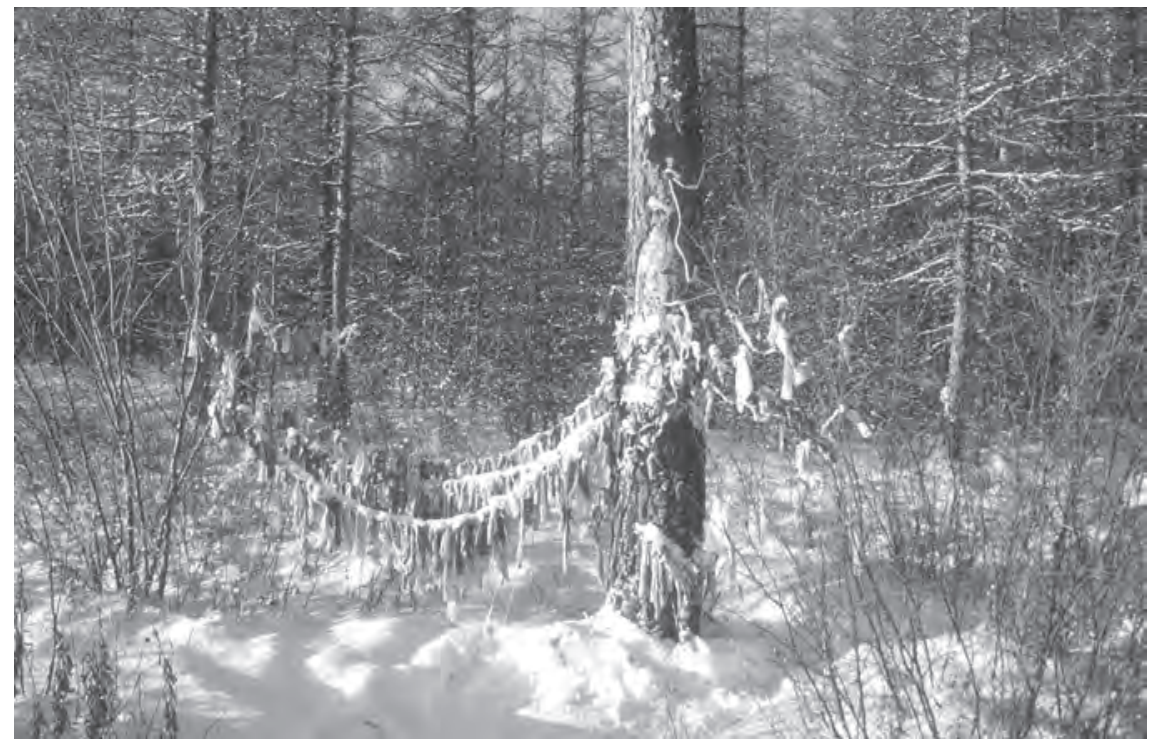

Приношение духу озера, зима 2001 г.

Мой интерес к шаманству начался с нескольких экспедиций к народу ладахи западного Тибета и Индии в 1980-е гг. Ладахи сохранили культуру и мировоззрение, включавшее шаманскую традицию, хотя их образ жизни постепенно изменялся под влиянием современных обстоятельств. В отличие от них, якуты были вынуждены оставить свои религиозные традиции под давлением атеистической политики в Советском Союзе. Мне было интересно, действительно ли они отказались от своей традиционной культуры? Этнологи, которых я встретила на конференциях, говорили о возрождении шаманства среди якутов. И мне захотелось самой увидеть современную религиозную ситуацию в республике, познакомиться с мировоззрением якутов, оценить состояние шаманской традиции. 
Я была не первым зарубежным антропологом, заинтересовавшимся возрождением шаманства среди народа Саха после распада СССР. Чуть раньше Марджори Балзер после своих экспедиционных исследований среди народа ханты в 1986 и 1991-1995 гг. совершила поездку в Якутию. Но ее скорее занимали политические аспекты возрождения шаманства [Balzer, 1993; Balzer, 1996]. Что касается меня, то мне были интересны космология и анимистические представления, которым и посвящена данная статья.

С 2001 г. мне больше не пришлось бывать в Якутии, но я обратила внимание на то, что шаманство якутов остается предметом пристального и активного интереса этнологов и антропологов. Так, например, на 10-й конференции Международной ассоциации исследователей шаманизма, проходившей в Варшаве в 2011 г., было заявлено несколько

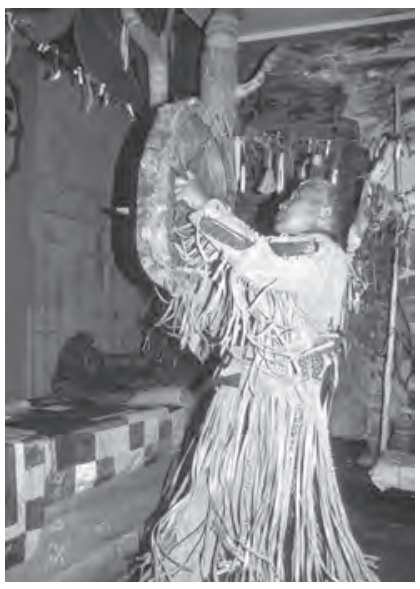

Шаман (преподаватель Якутского колледжа культуры и искусств) демонстрирует автору, как он передает студентам опыт проведения шаманских ритуалов докладов, посвященных возрождению шаманства и его связи с современным искусством якутов; шаманской тематике в наскальных рисунках, найденных в Республике Саха; современным шаманам и истории шаманства [Program and Abstracts]. Доклады Зола и Розвадовского были позднее напечатаны в журнале Shaman [Zola; Rozwadowski].

Эта статья, основанная на моих полевых исследованиях 1994 г., уже выходила в 1997 г. [Yamada, 1997], но, я надеюсь, ее публикация на русском языке вносит определенный вклад в понимание шаманства и анимистических элементов культуры якутов (саха) и имеет смысл для современных исследователей.

\section{Постановка проблемы}

Якуты хорошо известны в этнографии своими анимистическими верованиями и шаманскими практиками. Согласно имеющимся сведениям, пространство вселенной в представлении якутов трехмерно, населено большим количеством различных духов, с которыми вступают в контакт «белые» (aiyy oyuun ${ }^{1}$ ) и «черные» (abaahylaakh oyuun).

В результате христианизации в XVII в. были запрещены практики «белых шаманов» (aiyy oyuun), которые, по представлениям якутов, имели специальные заклинания для взывания о благословении к богам algus-toyuk и которые служили на благо людей. Что касается практики «черных шаманов» (abaahylaakh oyuun), лечивших болез-

${ }^{1}$ Здесь и далее все якутские термины даны в авторском варианте в английской транскрипции. - Прим. ред. 
ни и защищавших людей от злых духов, то они существовали до тех пор, пока советская власть в ходе атеистической кампании не начала борьбу с шаманизмом. С этого времени шаманские ритуалы якутов практиковались и передавались скрытно.

После распада СССР и выхода «Декларации о государственном суверенитете Якутской-Саха Советской Социалистической республики» в сентябре 1990 г. Якутия стала Республикой Саха (Якутия). Запрет на ритуалы шаманов и традиционные методы лечения был снят. С этого времени стали возрождаться шаманские практики, традиционные методы лечения и мировоззрение. Хотя ни один из шаманов (оуииn), практиковавших в начале 1990-х, не был знаком с процедурой кровавого жертвоприношения, они начали активно заниматься целительством.

Тайлор в своей книге «Первобытная культура» определил анимизм как веру в духов. Таким образом, анимизм в его различных формах можно считать базовой религией многих культур. Зачастую этот термин используется для обозначения любой формы веры в духов, воспринимается как нечто неизменное и ограничивается рамками религии. Однако такая трактовка не дает возможности понять, как и почему данное верование продолжает существовать до сих пор.

Между тем вера в духов не ограничена исключительно сферой религии в отдельно взятой культуре, так как она подразумевает более широкий взгляд на мир. Все представления о вселенной, душе и духах переплетаются и формируют целостное мировоззрение. Более того, религия неотделима от экологии, как я уже отмечала в исследовании о культуре народа айну [Yamada, 1994a; Yamada, 1994b]. На самом деле вера в духов - это отнюдь не статичное явление в культуре, оно постоянно изменяется. По мере того как меняется экология, меняется и вера народа или его видение мира. Вера в духов не является ни теорией, ни доктриной, ни чем-либо отмеченным окончанием «-изм». Но эту веру можно назвать целостным мировидением, основанным на сверхъестественном опыте.

\section{Концепция вселенной}

Общее представление якутов о вселенной можно реконструировать на основе этнографических публикаций XX в. [Czaplicka, p. 277-278; Jochelson, p. 103-104; Гоголев], а также данных моих полевых исследований следующим образом. Вертикально вселенная делится на три сферы: верхний мир (uwehe doydu), средний мир (orto doydu) и нижний мир (urlala doydu), сквозь которые проходит Древо жизни, то есть Мировое древо.

Считается, что верхний мир находится на небе и состоит из девяти уровней, каждый из которых населен своими божествами (aiyy или tangara). Верховный бог якутов - Urung Aiyy Toyon («белый соз- 
датель-господин»). В его образе персонифицировано солнце, он живет на самом высоком уровне в восточной части неба. Ulutuyer Uluu Toyon, который является хозяином abassy (злых духов; множ. abassylar) в верхнем мире и чья роль связана скорее с наказаниями, чем со счастьем, живет в западной части неба, хотя некоторые считают, что он принадлежит к aiyy (добрым духам; множ. aiyylar) [Гоголев, с. 16]. Таким образом, якуты считали, что верхний мир населяют не только добрые божества aiyy или tangara, но также и злые божества.

Средний мир - это мир земной, где люди живут вместе с духами, которые называются ichchi (буквально «хозяин, владелец», духхозяин; множ. ichchilar), и уӧr (души плохих людей после смерти). Также считалось, что внутри среднего мира есть еще один мир, который называется attun doydu, где живут ichchilar наряду с abassylar.

Нижний мир расположен под землей; там живут злые духи abassylar. Считается, что они «съедают» души людей, в особенности buor-kut (земную душу) человека².

Таким образом, якутская космология подчеркивает существование каждого из миров в его связи с характерными для него духами.

Кроме того, якуты также традиционно признавали важность горизонтального деления вселенной: восток и юг мыслились как территория добрых духов, в то время как запад и север - как царство злых. Одна из исследователей, Мария Чаплика отмечала, что ориентация во вселенной у якутов идет главным образом по горизонтали и состоит из двух частей, хотя существует и вертикальное деление на верхний, средний и нижний миры. При этом Чаплика считала, что вертикальное деление менее точное и не настолько важное, как горизонтальное. Поскольку злые духи abassylar присутствуют во всех трех делениях, ни один из вертикальных миров не ограничен лишь добрыми духами aiyylar [Czaplicka, 1914, p. 279].

Но все же якутские шаманы, признавая существование злых духов в верхнем мире, согласно полевым материалам, в целом связывают верхний мир с добрыми божествами aiyylar, а нижний мир c abassylar, божествами злыми. Ниже приведены их представления о верхнем и нижнем мирах.

\section{Верхний мир}

Якуты считают, что только шаманы, в особенности aiyy oyuun (белые шаманы), которые могут посещать верхний мир, имеют о нем детальное представление. Поэтому обладание знанием о верхнем мире считается показателем того, что человек является белым шаманом.

2 Далее будет показано, что у человека, по представления якутов, имеется три души, одна из которых - земная. - Прим. ред. 
Молодая шаманка Д. (около 40 лет) рассказала о верхнем мире следующее, ссылаясь на свой магический опыт пребывания там:

Я думаю, что во вселенной для меня существует три olobokh (место, сиденье): одно - в верхнем мире, второе - в среднем и третье - в нижнем мире. В своих снах я могу улетать в верхний мир, оставаясь при этом в среднем мире. У меня есть специальное olobokh. На нем я поднимаюсь в верхний мир, используя специальную веревку $b w e$.

То, как я улетаю в верхний мир, я держу в секрете и не рассказываю в деталях. Однако могу сказать, что я летаю наверх с помощью очень длинной веревки из конского волоса, которая уберегает меня от несчастных случаев. Я даже могу летать вокруг солнца. Если кто-то притронется к этой веревке, он может заболеть. Olobokh и bwe, которые используются для полетов в верхний мир, предназначены только для меня.

В верхнем мире я встречаю его жителей. Они высокие и красивые. У них большие голубые глаза и белая кожа; они напоминают европейцев. Они живут в домах с полуовальными окнами. Верхний мир богат красками и цветами. Он настолько ярок и полон света, что иногда глазам становится больно. В верхнем мире нет времен года и ночей. Я летаю в верхний мир лишь иногда. После возвращения оттуда я обычно чувствую, что во мне стало больше силы.

Солнце принадлежит верхнему миру, а луна и звезды находятся между верхним и средним мирами. Солнце в верхнем мире настолько яркое, что даже сложно его сравнить с тем, которое мы видим в нашем мире.

Я не много видела богов в верхнем мире. Я видела только Иисуса Христа, одну женщину-богиню (tangara) и пару других богов. Иисус и женщина-богиня дали мне фотографию, попросив меня присматривать за людьми в мире. Поэтому я верю, что получила способность излечивать не только якутов, но также людей других национальностей.

Верхний мир по представлениям якутских шаманов полон света, внешне его обитатели отличаются от якутов, они дают людям среднего мира сверхъестественную силу. В случае шаманки Д. представление о боге в верхнем мире включало элементы христианской традиции.

Из сведений пожилого шамана К.:

Верхний мир, расположенный на небе, состоит из девяти уровней, каждый из которых имеет своих обитателей, то есть tangara (божества, которые живут только в верхнем мире). На вершине неба живет Urung Aar Toyon, который является главным богом среди aiyy tangara (добрых божеств). Якуты верили, что в верхнем мире живут не только aiyylars или tangara (добрые божества), которые побуждают людей делать добро, но также и ajaraidar, которые принадлежат abassylar. Источник добрых сил находится на востоке, тогда как источник злых сил - на западе. В верхнем мире происходит борьба добра и зла, точно так же как у нас в среднем мире. Кроме того, в верхнем мире живут также духи иaru tordo (источники болезней). 
Шаман Г. рассказывал, что он летал в верхний мир попросить помощи у высших божеств, когда его пациент был очень слаб. По его мнению, в верхнем мире есть источники некоторых болезней. Он добавил, что, воспользовавшись методом гипноза, летал в верхний мир вместе с salgyn kut (воздушной душой) своего пациента. По словам шамана, у пациента остались хорошие впечатления от встреч с духами и умершими людьми во время его пребывания в верхнем мире. $\mathrm{OH}$ также предположил, что получил свои сверхъестественные способности от божеств верхнего мира.

Таким образом, шаманы указывали на существование злых сил в верхнем мире. При этом считалось, что обитатели верхнего мира дают сверхъестественную силу шаманам для излечения людей. Поэтому все шаманы подчеркивали добрый характер верхнего мира, не желая, чтобы их считали черными шаманами.

\section{Нижний мир}

Хотя наличие злых духов предполагается во всех трех мирах вселенной, все-таки сосредоточены они в нижнем мире, в который попадают по специальному каналу, называемому «вода смерти». То, как шаманы представляют подземный мир, видно из следующих трех примеров.

Шаман К. дал довольно подробное его описание:

Якуты верят, что нижний мир является темным, там нет ни солнца, ни луны. Его поверхность не совсем гладкая, она скорее топкая и илистая. Там есть озера, где живут рыбы с перевернутой чешуей. Шаману очень сложно ходить по нижнему миру. Царство abassylar и большинство источников болезней находятся в нижнем мире. Мы представляем себе источники болезней в виде духов, что-то вроде ichchilar из среднего мира. Они являются чем-то вроде злых духов, которые могут принимать самый разнообразный облик, например, они могут быть животными с двумя головами.

Шаманка В. сообщила, что ее душа никогда не летала в нижний мир, но у нее есть некоторые знания о нем:

В нижнем мире, где сосредоточена негативная энергия, живут abahe (она всегда использовала термин abahe для обозначения злых духов. - Т. Я.). На земле можно найти географические точки, где сосредоточение негативной энергии очень велико. Считается, что такие точки - это ворота в нижний мир. Я думаю, что abahe - это и есть сама негативная энергия. Иногда я чувствую эту негативную энергию в теле пациента, и я обычно извлекаю ее так, как будто бы я медленно тяну веревку из его тела. 
Для шаманки В. нижний мир был источником негативной энергии, которая влияла на людей в среднем мире. Она также считала, что люди заболевали из-за этой негативной энергии и что именно шаманам предназначено было избавлять людей от нее.

Шаманка Д. рассказала о своем опыте пребывания в нижнем мире:

Он очень темный, и очень сложно что-либо разглядеть в нижнем мире. У некоторых жителей там есть скот, в то время как в верхнем мире его нет. Создается ощущение, что нижний мир покрыт темными облаками. Я захожу в нижний мир через специальный проход, который называется aartyk, и у каждого шамана он свой. Этот проход настолько узкий, что мне обычно приходится ползти. Мое пребывание в нижнем мире было очень мимолетным.

Обитатели нижнего мира серые, слабые и неприятные. Они передвигаются очень медленно. Люди этого мира говорят мне, что нижний мир темный, потому что там нет солнца, и просят меня принести им туда солнце. Они говорят, что могут видеть солнце, лишь когда я спускаюсь вниз.

Abassylar живут в нижнем мире. Я думаю, что добрые духи ichchilar тоже живут там. Однако они поселились там совсем недавно. Это произошло, когда мы, якуты, начали уделять особое внимание совершению добрых дел и уважать природу.

Каждый раз, когда я путешествую в нижний мир, я пытаюсь возвратиться в средний мир как можно скорее. Поэтому я не знаю много об abassylar в нижнем мире.

Как видно из приведенных фрагментов интервью, нижний мир представлялся шаманам очень темным, полным злых сил, в отличие от верхнего мира. Все шаманы говорили о недобром характере нижнего мира. Ни один из них не хотел подробно о нем рассказывать.

Верхний мир совершенно четко отделялся якутами от нижнего мира на основании того, что в нижнем мире не живут добрые духи. Нижний мир - это сам по себе источник зла. Можно заключить, что горизонтальное деление на территории добра и зла становится все более распространенным.

\section{Представление о духах}

Представления якутов о духах тесно связаны с делением вселенной [Czaplicka, p. 277-280; Jochelson, p. 103-106; Гоголев]. Как уже упоминалось, в верхнем мире, согласно этим представлениям, живут aiyylar или tangara и ajaraidar (злые духи), в среднем мире - yör (привидения), ichchilar и kut (души людей). В нижнем мире обитают abassylar. В ходе полевых исследований удалось собрать информацию о том, как все эти духи описывались и различались шаманами. 


\section{Понятие души}

Традиционно якуты верили, что человек состоит не только из плоти, но в нем есть и что-то нематериальное. Шаманка В. рассказала, что чувствовала существование души:

Одна из моих дочерей погибла в аварии. Я чувствовала, что она плакала, когда ее тело принесли домой. Я видела слезы на ее глазах. Душа может быть рядом с мертвым телом перед похоронами.

Считалось, что нематериальную сущность человека составляют kut (обычно переводится как «душа»), sur (жизненная сила) и tying (дыхание человека). Понятие kut, как правило, включает три категории: bour-kut, iya-kut, (материнская душа) и salgyn-kut. Tying присущ человеку, животным и растениям, а kut и sur - человеку и животным [Czaplicka, p. 279-280].

Якуты верили, что материнская душа - это самый важный элемент, который передается ребенку от матери. Она остается неизменной в течение жизни человека и определяет его индивидуальность и судьбу. Якуты считали, что земная душа связана прежде всего со здоровьем и физическим развитием человека. Воздушная душа связана с умственными возможностями, и в ней заключен интеллектуальный потенциал. Считалось, что два последних элемента души могут меняться и человек получает их после своего рождения [Романова, 1994, с. 26].

Если земная душа «уходит», считалось, что человек умрет, так как земная душа - это тело, и оно возвращается на землю после смерти. Якуты также верили, что abassylar в нижнем мире всегда пытаются «съесть» земную душу. Когда человек спит, его воздушная душа может покидать тело. Считалось, что это часто приводит к болезни. Кроме того, якуты верили, что, когда кто-то умирает в семье, он может забрать с собой воздушные души своих любимых родственников. В этом случае обычно просили aiyy oyuun вернуть назад эти воздушные души [Суздалов-Саппалай].

Якуты также верили в существование привидений ( $у \ddot{r} r)$. Считалось, что души тех, кто умер в молодом возрасте или погиб насильственной смертью, тех, кто был похоронен без надлежащей церемонии, а также души шаманов и великих людей, становятся yёr [Czaplicka, p. 161]. Раньше были шаманы, которые получали свою силу от yör. В таких случаях считали, что yör были tangara [Романова, 1993].

По словам шаманки Д., она могла почувствовать, что у человека было tying chan - «плохое (загрязненное) дыхание», которое надо было «прочистить» (tying означает «дыхание», а chan - «плохой»). Она в таких случаях плевала и этим очищала tying chan, и делала это каж- 
дый раз, когда чувствовала загрязненное дыхание другого человека. Таким образом, tying используется как термин, означающий состояние человека.

У опрошенных нами якутских шаманов сохранился традиционный взгляд на душу человека. Шаманка Д. рассказала о понятиях кut и kut-sur, а также о душах умерших:

Когда мы говорим про kut, существует три варианта. Iya-kut (материнская душа) является источником всего. Salgyn-kut (воздушная душа) является нашей жизнью. И наконец, bour-kut (земная душа) - наше тело. Kut-sur включает в себя все эти три kut.

Люди, которые получили дар от природы, после смерти дают о себе знать. Их сила остается в среднем мире. После смерти они могут напоминать о себе в виде снегопада или дождя. Они не умирают полностью.

Kut-sur обозначает способность реализовывать потенциал человеческой души. Я думаю, что, если у человека есть кut-sur, это значит, что он защищен от вредного воздействия. Человек получает кut-sur от природы. Мы живем в среднем мире и имеем кut-sur. Мы должны развивать его в гармонии с природой. При рождении наш кut-sur находится на высоком уровне. С его развитием развиваются и наши способности. Мы должны попытаться использовать все способности, которые имеем от рождения.

Но бывают случаи, когда ребенок рождается с открытым кut-sur. Это означает, что его кut-sur слабый и незащищенный. В данном случае нужно быть очень внимательным к ребенку. Мы не должны давать ему повода плакать и должны относиться к нему с нежностью. Он нуждается в наших улыбках и доброте. Когда такой ребенок становится взрослым, его открытый кut-sur закрывается. Возможно, это происходит в возрасте двадцати лет. После этого он становится сильнее. Мы должны реализовывать свой потенциал согласно нашему собственному кut-sur.

Я думаю, что кut - это та самая сущность, которая определяет существование человека в этой жизни. Если я говорю, что у кого-то есть $\kappa u t$, это значит, что у него есть способность слышать, видеть или что у него есть кровь и т. д. Я думаю, что sur относится к некой силе, поэтому мы также говорим, что кut-sur - это что-то вроде жизненной силы.

После смерти душа умершего остается в среднем мире на протяжении сорока дней. Затем душа превращается в птицу или растение. Душа хорошего человека вернется назад в средний мир в виде птицы.

В течение сорока дней мы приносим мертвым еду: топленое масло, соль и сахар. Топленое масло символизирует озеро, где птица может плавать, соль - снег, а сахар - лед. Каждое утро мы смотрим, не появились ли какие-либо знаки на тех продуктах, которые мы положили ранее.

Душа плохого человека превращается в уӧr. Она не может вернуться в средний мир и живет между средним и нижним мирами. 
Таким образом, согласно представлениям шаманки Д., кut имеет три элемента, что сходно с традиционной якутской концепцией, - при этом kut должен сопровождаться sur (некой силой), чтобы человек смог реализовать свой потенциал. Более того, она полагает, что ребенок имеет высокий потенциал kut-sur, так как он, как и природа, очень чист. Тем самым она подчеркивает идею о том, что важно находиться в гармонии с природой, чтобы развивать свою способность kut-sur, которая дана с рождения. Для нее природа - это источник всего.

Еще одна шаманка объяснила суть $k u t$ и душ мертвых следующим образом:

Kut-sur, человеческая душа, - это сущность человека. Когда человек умирает, кut покидает его тело. Перед похоронами умерший все еще может чувствовать. На протяжении первых трех дней после похорон $k u t$ находится в доме покойника. До девятого дня киt находится рядом с домом. После этого он скитается по среднему миру. Только лишь через сорок дней душа может уйти в kuyar (космическое пространство), которое расположено над девятым небом. Если, по мнению покойника, его похороны были не очень хорошими, его душа обычно остается в среднем мире даже после сорока дней.

Шаман Г. рассказал, что для души умершего существуют три пути.

Один ведет в верхний мир, если человек чист и не совершал плохих поступков. Другой ведет в нижний мир, если человек совершал злодеяния. Последний путь - стать уӧr в том случае, когда душа не может уйти ни в верхний, ни в нижний мир.

Шаман К. считал, что только люди имеют kut-sur, у животных после смерти его нет.

Животное умирает полностью. Только у человека есть kut-sur, который продолжает существовать после смерти. При естественной и ненасильственной смерти человека bour-kut возвращается на землю. Iya-kut уходит в космос. Если человек умирает насильственной смертью или совершает самоубийство, то он становится $y \ddot{r} r$.

Согласно его сведениям, если шаман не обладает большой силой, его душа остается в среднем мире в течение 40 лет после смерти, для шамана средней силы - 200 лет, и душа сильного шамана остается в среднем мире на протяжении 400 лет.

Якуты верят, что кut умершего человека улетает в космос. После того как душа, в частности материнская душа, там очистится, она может переродиться в среднем мире. Таким образом, жизнь души можно представить в виде цикла. При этом цикл, который проходит душа шамана, очень долгий, поэтому количество шаманов, физически живущих в среднем мире, уменьшается. 
Воздушная душа тесно связана с материнской душой, иногда их даже не выделяют в отдельные понятия. После смерти воздушная душа может оставаться в среднем мире как воздух.

Из приведенных высказываний видно, как якуты концептуализируют человеческую душу. Старший шаман К. объяснил, что kut и kut-sur это два неотделимых друг от друга понятия, и это относится только к человеку. Животные не имеют kut-sur и умирают после того, как их убили. Понятие души связано с силой и исключительностью шамана.

Жизнь души интерпретируется как цикл. Однако не все элементы души, а лишь материнская душа может возродиться. Якуты считали, что материнская душа уходит в верхний мир, где она очищается и, по велению Urung Aiyy Toyon, перерождается в среднем мире. Таким образом, шаманы сохранили традиционное якутское поверье, что беременность происходит вследствие передачи материнской души женщине [Романова, 1994, р. 26].

Согласно некоторым источникам, у якутов существовало поверье, что мертвые уходят в другой мир и живут там, как жили в этом мире [Harva, p. 327, 337]. Однако нам не удалось получить такую информацию.

Некоторые говорили, что душа уходит в космос спустя сорок дней после смерти. Другие говорили, что душа вернется в средний мир в виде птицы или животного. Третьи утверждали, что только лишь материнская душа уходит в космос после смерти.

Также считается, что душа плохого человека остается в среднем мире после смерти. Yör (злой дух) приносит несчастья своим живым родственникам. Именно поэтому у якутов сохранился страх перед yör. По сообщению шаманки Д., семья, в которой кто-то умер, должна узнать, во что превратилась душа их родственника: это можно сделать, расшифровав знаки на еде, которую оставляют мертвым.

\section{Aiyylar и Tangara (добрые божества)}

Как уже упоминалось, aiyylar и tangara считались добрыми божествами в верхнем мире, которые побуждают людей делать добро. Не совсем ясно, на каких именно уровнях верхнего мира живет каждое из божеств. Однако общепринятым считалось, что Urung Aar Toyon (Urung Aiyy Toyon), Белый Благодетельный Господин, глава aiyylar, живет на девятом уровне (на вершине) верхнего мира. Его воспринимали как главного создателя и отца богов. Он живет в восточной части неба с женой и семьей [Harva, p. 137-138, 148; Гоголев, с. 28; Романова, 1994, р. 46-59].

Шаман К. описал и других божеств верхнего мира:

Jurgha Haan, который знает судьбу людей, и Odung Haan, который ею управляет, живут на восьмом уровне. Они владеют полной информацией о людях, живущих в среднем мире. Якуты считают, что у них есть писари, 
которые записывают жизнь и судьбу каждого человека с рождения и до смерти.

Suge Toyon (Бог грома и молнии) живет на седьмом уровне. Считается, что он убивает злых духов, которые прячутся в деревьях и домах. Якуты верят, что звук грома - это звук копыт его лошадей.

Josegei Toyon (Бог-покровитель лошадей) и Hotoi Aiyy (Бог орлов), покровитель якутов, живут на шестом уровне.

Alam Khotun (Богиня-покровительница скота) живет на пятом или четвертом уровне.

Uluuru Cuorun Toyon (Великий Бог-Ворон), чья роль не совсем ясна, но считается, что он дает людям вороных (цвет ворона) коней. Он живет на четвертом уровне.

Ayisyst (Богиня рождения) помогает женщинам разрешиться от бремени, она живет на втором или первом уровне. Ieykhsyst (защитница людей) ее роль сходна с ролью Ayisyst, она также обитает на востоке, на нижнем уровне верхнего мира. Ieykhsyst может давать женщинам желание к деторождению, в то время как Ayisyst на самом деле дарует детей, то есть помогает женщинам реализовать их желание иметь детей. Раньше якуты считали, что если у женщины не было детей, значит, Ieykhsyst и Ayisyst были оскорблены ее плохим поведением и лишали ее возможности иметь детей.

По мнению шамана, боги tangara распределены иерархично по девяти уровням во главе со своим создателем; они не являются богами природы, их компетенции связаны с благополучием якутов, также они покровительствуют скоту и лошадям. Можно заключить, что tangara контролируют человеческую жизнь.

Д. рассказала, что один из богов в верхнем мире научил ее, как можно очистить дыхание путем плевания. Таким образом, все опрошенные шаманы акцентировали внимание на том, что они должны были сами учиться способам излечения пациентов. Кроме того, шаманы должны были держать в строжайшем секрете то, как они получили свои сверхъестественные способности от aiyylar или tangara из верхнего мира. Можно заключить, что tangara - это божества, которые считались источником силы шамана, каждый со своей определенной специализацией. Также существовало мнение, что способности шамана зависят от божества, с которым он встречался во время полетов своей души.

\section{Ajaraidar и Abassylar (злые духи)}

Злые духи верхнего мира называются ajaraidar. Якуты верят, что Ulutuyer Uluu Toyon - это главный бог злых духов в верхнем мире. Однако он имеет очень сложный образ. Согласно исследованиям Гоголева, Ulutuyer Uluu Toyon упоминается среди пантеона богов якутов. Однако одни причисляют его к abassylar, другие - относят к aiyylar. 
Еще один источник указывает на то, что он живет в южной или югозападной части неба на нижнем уровне и что его младшая дочь является богиней-покровительницей скота. В любом случае Uluu Toyon считался могущественным богом и был чаще связан с наказаниями.

Считалось, что Cuorun Toyon (Бог-ворон), живущий на четвертом уровне неба, не принадлежит aiyylar, а является братом Uluu Toyon (глава ajaraidar). В среднем мире ворон - это его сын или младший брат [Гоголев, p. 14, 16]. В любом случае главный бог есть как у добрых божеств, так и злых.

Шаман К. так объяснил понятие ajaraidar, которые являются abassylar (злыми духами) в верхнем мире:

Ajaraidar (злые божества верхнего мира) изначально принадлежали к tangara в верхнем мире, но они восстали против Urung Aar Toyon и стали управлять всеми злыми силами в верхнем мире. Ajaraidar всегда вызывают в людях плохие чувства, которые приводят к ссорам, дракам и убийствам. Ajaraidar плохо влияют на людей, в то время как все хорошее связано с tangara (добрыми божествами).

Он также сообщил, что под влиянием ajaraidar человек становится более агрессивным и может причинить вред другим:

Мы боимся ajaraidar, не обращаемся к ним и не задаем им вопросы. Если кто-то перестает уважать tangara, это значит, что этот человек больше не находится под защитой tangara. Именно в этот момент ajaraidar оказывают свое влияние на людей и побуждают их совершать зло.

Шаман К. также говорит, что некоторые abassylar верхнего мира, то есть ajaraidar, пытаются навести на людей болезни, связанные с глазами и зрением. Поэтому оуиип (шаманы) должны уходить в верхний мир, чтобы найти источник или причину заболевания.

Различие между abassylar нижнего мира и теми, кто живет в среднем или верхнем мирах очень простое. Abassylar нижнего мира более могущественны, и они «едят» земную душу человека. Поэтому якуты боятся больше всего именно abassylar нижнего мира. Однако считается также, что только те люди, которые не защищены ichchilar (духами-хозяевами среднего мира), подвержены вредному воздействию abassylar. Большинство верят, что, пока они уважают ichchilar, они не подпадут под влияние abassylar.

\section{Духи-хозяева - ichchilar}

В среднем мире живут как люди, так и различные духи. Якуты верят, что одушевленные и неодушевленные предметы среднего мира имеют нематериальную сущность ichchilar. Обычно этот термин переводят как «духи-хозяева». 
Считается, что ichchilar имеют человеческий облик: старика, пожилой женщины, мальчика или ребенка. Якуты боятся употреблять само слово «ichchi», и на упоминание имени духа-хозяина наложен запрет. Поклоняясь ichchilar, духам земли, огня, охоты, рыбалки, воды и т. д., к ним, как правило, обращаются со словами «бабушка» или «дедушка».

Дух земли, который называется Aan Doydu Ichchite (Мать-Земля) или Sir Ichchite (Дух Земли), - это главный женский дух среднего мира, связанный с плодородием. Одна из опрошенных шаманок сообщила, что дух земли - это женщина-мать, так как она порождает все на земле.

Sir Ichchite различается в зависимости от местности. Например, когда люди отправляются куда-то, они обычно «кормят», то есть делают подношения Sir Ichchite, перед тем как пересечь границу его территории. У каждого места есть Sir Ichchite. Одна из шаманок рассказала:

Я думаю, что Sir Ichchite - это самая сильная шаманка, потому что я обычно чувствую какое-то тепло там, где живет Sir Ichchite. Если мы не будем ее уважать, она наведет на нас болезни или несчастные случаи. Подношения Sir Ichchite обычно помогают нам в дороге.

По сведениям Гоголева, Sir Ichchite живет в Мировом древе (Aarkuduk-mas). Древние якуты верили, что не только Doydu Ichchite (то же, что Sir Ichchite), но и Uot-mas Ichchite (Дух растительности) живет в древе жизни. Якуты выбирают дерево, обычно лиственницу, для почитания и поклонения Doydu Ichchite. Дети Doydu Ichchite, которых называют Elekëjelekë, покровительствуют флоре. Якуты верили, что под их дыханием деревья и травы становятся зелеными. В случае если у женщины не было детей, они просили их у этого духа, говоря: «Ieykhsyst и Ayisyst не дали мне детей, поэтому мне приходится просить это благо у тебя» [Гоголев, с. 17-19].

Каждую весну якуты совершают ритуал sichi uyarna (буквально «висящая веревка из конского волоса»), чтобы принести жертву Aan Doydu Ichchite. Для этого ритуала обычно выбирают березу и вешают на нее пучки конского волоса, корзиночки из березовой коры, разноцветные ленточки и т. д. Якуты садятся под дерево, и глава семьи обращается к духу огня и подливает в огонь кумыс (алкогольный напиток из кобыльего молока). Затем якуты устраивают трапезу под деревом, танцуют и поют песни в честь духа. Таким образом они просят плодородия у Aan Doydu Ichchite.

Дух огня - самый почитаемый и независимый от других. Костер это место, где обитает Uot Ichchite (Дух-господин огня). Якуты представляют себе дух огня в виде старца, который обладает большими возможностями и может получить любую силу от божеств верхнего мира. Он живет там, где есть огонь. В современных домах это может быть духовка газовой плиты, обычно там ему и делают подношения, 
оставляя еду. Якутам необходимо постоянно выражать свое уважение этому духу.

Шаманка В. рассказала, что при лечении пациента она всегда консультируется с духом огня. Она также сообщила о своих опасениях:

Если я нерегулярно оставляю в плите подношения, дух огня может открыть дверцу духовки или прийти ко мне во сне и попросить покормить его. Если мы не будем оставлять ему еду, дух может разозлиться и навлечь на нас серьезные болезни.

Еще один из опрошенных шаманов рассказал об этом следующее:

Все в жизни якутов связано с духом огня, чья главная роль заключаются в защите и очищении. Только благодаря духу огня зимой мы можем готовить пищу и не замерзать. Мы выживаем только благодаря сохранению нашей традиции почитания этого духа.

Огонь занимает большое место в жизни якутов, поэтому мы делаем подношения духу огня в виде масла, кумыса, табака и чайных листьев. Однако ему нельзя оставлять мясо или рыбу, то есть продукты охоты или рыболовства.

В каждом ритуале якуты прежде всего должны развести огонь, где они смогут оставить подношения. После этого дух огня будет защищать людей. Даже в шаманских ритуалах оуиип сначала разводят костер, вызывая тем самым дух огня, а затем вызывают Aan Doydu Ichchite (Хозяйку мира) и их духов-помощников. Считается, что дух огня помогает шаманам по дороге в другие миры.

Baianai - это дух охоты и рыбной ловли. Он обычно живет в лесу. Все животные в лесу являются родственниками Baianai. Якуты представляют его в виде старика. В лесу все имеет ichichi. Когда человек идет в лес на охоту, Baianai (ichchi охоты) отдает охотнику свою долю, он посылает ему животных.

Поэтому во время охоты охотник должен призывать Baianai, а также духа огня. Перед тем как вызвать Baianai, охотник должен сначала «накормить» огонь, разведя костер. Это также символизирует то, что он кормит Baianai. Через огонь он просит у Baianai удачной охоты. После этого Baianai может дать ему эту возможность. После возвращения с охоты охотник делает другие подношения духу огня в своем доме. Так как он просит у Baianai мясо или рыбу, он не может предлагать эти продукты духу огня.

Якуты также поклоняются духу воды, которого представляют в виде пожилой женщины, и к ней обращаются, используя слово «Abe» («бабушка»). Перед тем как отправиться на рыбалку, якуты должны сделать подношения как духу огня, так и духу воды. Обычно бросают немного хлеба в реку или озеро и просят о помощи.

У каждой реки или озера есть свой собственный дух ichchi. Раньше считалось, что духи воды живут под водой и что они рождаются, 
живут и умирают так же, как и якуты. Однако во время полевых исследований 1994 г. такой информации получить не удалось.

В рассказах шаманов выявляется характер природы ichchilar как бессмертного духа-хозяина, высшего по отношению к материальной субстанции. Шаман К. воспринимал ichchi как некого духа, который является хозяином каждого предмета. Также он считал, что только у людей есть kut-sur (жизненная сила), тогда как у животных ее нет, и поэтому они умирают полностью. Шаман Г. говорил, что если у стола, стула или дома есть дух-хозяин, то его можно назвать ichchi. Сам же материальный предмет не имеет бессмертной сущности:

Когда мы сносим сарай или коровник, Khoton Ichchite (дух-хозяин коровника) обычно остается в дереве, которое затем используется для постройки нового коровника.

Есть одна история, связанная с этим поверьем. У одного моего соседа был старый сарай. Каждый год умирали одна-две коровы, поэтому он построил новый сарай. Но он построил его из того дерева, которое было в старом сарае. Таким образом, он не выпустил Khoton Ichchite, и коровы умирали снова.

Если дерево сарая сгнивает, тогда Khoton Ichchite остается в том месте, где стоял сарай.

Khoton Ichchite (буквально «хозяин коровника») считается самым маленьким по размеру среди других ichchilar. Этот дух живет на вершине столба в левом углу напротив входа. Сарай нужно чистить два раза в год. Также считается, что дух коровника помогает человеку с умственными недостатками или при проблемах с нервной системой. Кроме того, если люди не смогут установить отношений с этим духом, они рискуют потерять весь свой скот.

Однако бытовали и иные представления. Шаманка Д. утверждала, что в среднем мире было много ichchilar, с которыми якуты должны жить в гармонии:

Ichchilar есть у деревьев, животных, камней и всех вещей. Я думаю, что на земле все вещи живые, так как каждая вещь имеет своего духа. Очень сложно объяснить, что же такое ichchi. Этот дух живет в ком-то или в чем-то, но мы не можем его увидеть. Это и есть ichchi. Например, каждая корзина имеет своего ichchi, подобно тому как у каждого человека есть своя душа.

Некоторые разделяли понятия tangara (божество) и ichichi (духхозяин), однако я их не разделяю. Я думаю, что они оба связаны с природой. Tangara - это источник природы. Наше почитание солнца тесно связано с Urung Ayii Toyon. Мне не нравится использовать слово tangara по отношению к вещам, так как солнце, ветер и облака - все имеет ichchi. 
У меня есть свои собственные священные деревья - береза и лиственница. Я могу обращаться к этим деревьям с просьбой вылечить женщин, которые не могут иметь детей.

Когда животное убивают, его ichchi может улететь и вселиться в когонибудь, и тогда характер этого человека начинает напоминать характер животного. Например, мы иногда говорим, что кто-то хитер как лиса. Ichchilar также могут вселиться в растения и животных. Поэтому после того, как животное убито, ichchi может снова вернуться в природу.

Согласно мнению той же шаманки, ichchi - это нематериальная ипостась всего сущего (за исключением людей) в среднем мире. Хотя она разделяла понятия ichchi и kut, но считала, что оба они имеют сходные характеристики: отдельное существование и циклическое движение от рождения к смерти. В этом отношении ее понимание отличается от традиционного понимания ichchi как духа-хозяина. По ее мнению, якуты не должны причинять духам вред:

Я думаю, что все ichchilar добры, пока мы не причиняем им вред. Если мы отправляемся в лес на охоту, то мы должны «покормить» духа огня. В этом случае на охоте нам будет сопутствовать удача. Природа добра к нам, и мы, в свою очередь, должны ее уважать.

Таким образом, для нее ichchi - это нематериальная сущность всех вещей, а также животных и растений этого мира.

Шаманка Д., как упоминалось выше, считала, что ichchi не отличаются от tangara в верхнем мире. Ichchilar в среднем мире добрые по своей природе. В отличие от духов из нижнего мира, ichchilar не могут навредить людям: если те не уважают духов, ichchilar просто перестанут их защищать.

Шаманка В. утверждала, что ichchilar бывают злобными, но люди могут ими управлять, если у них есть нужная энергия и сила:

Я никогда не видела abahe (то же, что abassy), но они, возможно, существуют. Возможно, ichichilar и abahe - это одно и то же. Уважение ichchilar приносит им пользу. Если люди не уважают их, то ichchilar могут навредить им: например, ichchilar могут начать вести себя как abahe. Я люблю гулять на природе, но я еще ни разу не встречала abahe.

Согласно ее представлению, ichchilar и abassylar имеют двойственный характер.

Аналогичный взгляд на природу ichichi был представлен шаманом Г.:

Существует много видов abahe (abassylar). Abahe могут быть ichchilar, то есть хозяевами каких-либо предметов - например, дома, скота и т. д.

У ichchilar двойственная природа: они могут быть как добрыми, так и злыми. Если ichchilar любит кого-то, тогда он хорошо относится к этому 
человеку. В противном случае он вредит ему. Между человеком и ichchilar могут быть как хорошие, так и плохие взаимоотношения.

Abassylar нижнего мира и среднего мира отличаются друг от друга. Abassylar нижнего мира имеют больше силы.

Таким образом, якуты боятся ichchilar, хотя и отличают их от духов нижнего мира (abassylar), которые «едят» земные души людей. В представлениях шаманов ichchilar не являются обязательно злыми и, проявляя к ichchilar уважение, можно построить с ними хорошие отношения.

Считается, что у якутских шаманов много духов-помощников (komolohochi ichchilar), которые их сопровождают, оставаясь невидимыми для обычных людей. Шаманка Д. упомянула нескольких из своих многочисленных духов-помощников, не раскрывая их имен: kutaluck (что-то вроде белого лебедя), kuba (белый лебедь), turuya (журавль), sor (ворон), лось и бык. Она сообщила, что может обернуться птицей или даже рыбой. Она утверждала, что путешествовала в верхний мир с помощью духа птицы и в нижний мир через «воду смерти» с помощью духа рыбы.

Якутские шаманы обычно по-разному просят о помощи в зависимости от проблемы. При этом они обращаются к разным духам, так как у каждого из них своя роль; животные и птицы обычно помогают духам шаманов и связаны с шаманскими практиками.

\section{Духи, дающие шаманам силу и способности}

Как было сказано выше, якуты верят в различных духов, таких как aiyy, tangara, ajaraidar, abassylar, ichchilar и yör. Считается, что большинство из них даруют сверхъестественные способности шаманам. Якуты разграничивают имена и роли шаманов согласно их «специализации».

В исследовании Романовой [Романова, 1993] указано, что термин оуиип (шаман) включает по меньшей мере семь подкатегорий шаманов с различными функциями:

1) Kuhagan - злой, вспыльчивый шаман, который не помогает людям. Он всегда пытается применить черную магию к хорошим людям. Его единственное предписание - «есть» людей.

2) Aiyy oуuиn - помощник и покровитель людей, у которого есть специальные взывания о благословении к богам (algus toyuk). Он не «ест» людей или скот. Шаманы, которые получили свои задания от Urung Aar Toyon в верхнем мире, называются urung aiyy oyuun.

3) Yohetten tuttarbut oyuun, будучи безумным, получил задание от богов верхнего мира. Обычно он лечит слабоумие и болезни, связанные со зрением.

4) Alaraatan tuttarbut oyuun получил свою силу от богов нижнего мира. Он лечит только болезни, связанные с нижним миром. 
5) Yortten tuttarbut oyuun получил свою силу от yör (привидения). Он может действовать только в несложных ситуациях.

6) Emegetten tuttarbut oyuun получил свою силу от emeget (духа-покровителя оуиип). Он может лишь ловить злых духов, которые вызывают болезни.

7) Udagan - термин, обозначающий шаманку.

Каждый оуиип способен заменять другого, однако он может достигнуть результатов, только следуя своему заданию. Каждый оуиип находится в контакте с разными abassylar. Считалось, что у хорошего oyuun была мать среди животных, дочь и сын среди abassylar и tuttarbut emeget (его собственный бог-покровитель tangara).

Таким образом, различия существуют как в представлениях о духах, так и относительно роли и способностей шаманов. Современные шаманы различают лишь aiyy oyuun и простых оуuиn, которые только лечат болезни. Большинство из них заявляют, что получили силу от богов верхнего мира и могут исцелять людей.

\section{Выводы}

Традиционно считалось, что каждый мир в вертикальном делении вселенной населен своими духами: верхний мир предназначен для tangara (богов), которые контролируют жизнь человека, для ajaraidar (злых духов), которые вызывают в людях плохие чувства, и для yӧr (человеческих привидений). Нижний мир населен abassylar (еще одни злые духи), которые всегда пытаются «съесть» земную душу человека. Горизонтальное деление соотносило восток и юг с территорией добра, а запад и север - с территорией зла.

По общепринятым представлениям духи не были наделены двойственной природой, то есть не сочетали в себе хорошее и плохое. Духи делились на пять категорий и в зависимости от своей хорошей либо плохой природы каждая категория находилась в определенных отношениях с людьми и играла свою роль в шаманских практиках.

Однако в последнее время появилась новая идея о том, что духи, особенно духи-хозяева, имеют двойственную природу, так как ichchilar часто отождествляют с abassylar. Хотя шаманы все еще противопоставляют добрых ichchilar злым abassylar. Также получила распространение идея о том, что от отношений с духами зависит, станет человек хорошим или плохим. Более того, по мнению одной из шаманок, tangara (божества верхнего мира) нельзя отделить от ichchilar (духов-хозяев в среднем мире), так как и те и другие связаны с природой. Таким образом, представления о добрых и злых духах сближаются.

Абсолютное зло ассоциируется главным образом с богами нижнего мира. Шаманы стали акцентировать мысль, что в верхнем мире нет злых духов, а каждый злой дух (ajaraidar) изначально является 
добрым по своей природе. В связи с этим распространилось представление о том, что верхний мир - это источник добра, а нижний мир - это абсолютное зло. Таким образом, шаманы, опираясь на собственный религиозный опыт, начинают по-новому смотреть на мир.

Что касается понятия о душе человека, то оно не изменилось; якуты считают, что душа состоит из трех элементов и один из них - воздушная душа - может улетать в другие миры, то есть в верхний мир и нижний. Поэтому сверхъестественный опыт шамана обычно представляет собой полет его души в другой мир для установления контакта с духами.

У якутов нет такого понятия, как «одержимость». Ясновидение они объясняют тем, что душа шамана может совершать полеты в будущее, - в отличие от народа айну в Японии или ладахи в западном Тибете, которые считают, что одержимость может порождать сверхъестественные способности [Yamada, 1993, p. 217-219; Yamada, 1994a, p. 69-70]. Таким образом, в каждой культуре отношение человека к духам и связанные с этим явления интерпретируются по-разному.

Согласно традиционным якутским верованиям, духи ichchilar это духи-хозяева материальных предметов. Ichchilar воспринимаются как реальность, выходящая за рамки отдельных материальных предметов. Считается, что у животных не сохраняется жизненной силы после смерти, у них нет бессмертной сущности, поэтому они умирают. На основании этого якуты четко противопоставляли животных, растения и неодушевленные предметы людям, так как только люди обладают душой kut.

Однако возникли новые взгляды, в частности о том, что каждый предмет имеет своего ichchilar, подобно тому как человек имеет свою душу, и ichichi убитого животного может вселиться в человека, другое животное или растение. Другими словами, появилось представление о возрождении, тесной связи людей и животных, цикличном движении душ в природе. Ichichi считается чем-то вроде бессмертной сущности, подобной душе человека. Кроме того, жизнь человека и природы находится в постоянном цикличном движении.

Таким образом, природа стала восприниматься как символ духов, а взаимоотношения между людьми и духами - как отношения человека и природы.

Вследствие этого каждый шаман имеет свое представление о другом мире, хотя идея о трехэлементном строении души по-прежнему существует. Как упоминалось выше, по мнению одного шамана, душа хорошего человека возвращается в средний мир, в природу, а душа плохого человека превращается в уӧr и будет жить между средним и нижним мирами; по мнению другого шамана, душа на сороковой день после смерти человека отправляется в загробный мир; третий считал, что души некоторых людей превращаются в уӧr (привидения), которые не могут уйти ни в верхний, ни в нижний мир. Представления современных якутских шаманов о вселенной и духах претерпевают 
изменения: появляется дуалистический взгляд на мир - реальный мир и мир духов. Взаимоотношения человека и духов больше идеализируются, они мыслятся как симбиоз человека и природы. В связи с этим развивается практика почитания природы.

Традиционный взгляд якутов на вселенную и духов значительно отличается от представлений народа айну [Yamada, 1994a; Yamada, 1994b]. Взгляд айну строится на противопоставлении двух миров: мира людей и мира богов. Они верят, что не только люди, но также и все вещи во вселенной, как одушевленные, так и неодушевленные, имеют ramat (душу) и что природные предметы - это проявление kamui (божеств). Хотя kamui, как и люди, могут быть добрыми и злыми, айну считают такую классификацию условной и не подразделяют kamui на абсолютно добрых и злых. При общении между kaтuі и людьми происходит взаимообмен, при котором kamuі как бы дополняют человека [Yamada, 1994a].

Несмотря на различия между традиционным пониманием о вселенной и духах у якутов и айну, некоторые представления, появившиеся за последние десятилетия у якутских шаманов, все же сближают их с айну: новое разделение на добрых и злых, новое представление о ichichi и об отношениях между людьми и духами. Так как айну занимались охотой и собирательством, поклонение природе было для них базовым принципом и для них характерен дуалистический взгляд на мир. То, что сегодня якуты очень обеспокоены защитой природы, может повлиять на представления шаманов и сформировать такой же дуалистический взгляд, в основе которого симбиоз человека и природы.

Таким образом, в процессе возрождения анимистических верований личный сверхъестественный опыт шамана и интерпретация этого опыта способны сыграть роль в создании нового взгляда на мир, поскольку вера в духов - это не теория и не доктрина, а целостное миропонимание.

Наконец, представления о духах непосредственно связаны с шаманскими практиками якутов. У якутов существовали разные типы шаманов в зависимости от того, какие функции они получили от духов. Хотя считалось, что они могли заменять друг друга, все же каждый обладал определенными компетенциями, которые помогали добиваться наилучших результатов в той или иной сфере. Большинство современных якутских шаманов выступают в качестве целителей. Новый взгляд шаманов на мир может внести новые элементы в сложившуюся шаманскую традицию либо породить новую.

\section{Список литературы}

Гоголев А. И. Мифологический мир якутов : Божества и духи-покровители. Якутск : Республиканский центр культуры и искусства им. А. Е. Кулаковского, 1994. $29 \mathrm{c}$. 
Романова E. H. Ойуннара // Ойунн : сборник по якутскому шаманизму. Якутск : Якутский институт языка, литературы и истории, 1993. С.7-9. (На якутском языке).

Романова E. Н. Якутский праздник Ысыах: истоки и представления. Новосибирск : Наука, 1994. 159 с.

Суздалов-Саппалай И. А. Айй Ойууна // Ойунн : сборник по якутскому шаманизму. Якутск : Якутский институт языка, литературы и истории, 1993. С. 47-50. (На якутском языке).

Balzer M. M. Changing Images of the Shaman : Folklore and Politics in the Sakha Republic (Yakutia) // Shaman. 1996. Vol. 4. No. 1-2. P. 3-16.

Balzer M. M. Shamanism and the Politics of Culture : an Anthropological View of the 1992 International Conference on Shamanism, Yakutsk, the Sakha Republic // Shaman. 1993. Vol. 1. No. 2. P. 71-96.

Czaplicka M. A. (1914). Aboriginal Siberia. Oxford : The Clarendon Press, 374 p.

Harva U. Die Religiosen Vorstellungen der Altaischen Volker / transl. by Katsuhiko Tanaka. Tokyo : Sanseido, 1989.

Jochelson W. The Yakut. New York, 1933. 227 p. (Anthropological Papers of the American Museum of Natural History. Vol. 33. Pt. 2).

Program and Abstracts of the $10^{\text {th }}$ Conference of the International Society for Shamanistic Research : Shamanhood and Its Art, Warsaw, 5-9 October 2011. Warsaw, 2011. $96 \mathrm{p}$.

Rozwadowski A. In Search of Shamanic Themes in Eastern Siberian Rock Art (Yakutis / Sakha Republic) // Shaman. 2014. Vol. 22. No. 1-2. P. 96-118.

Yamada Takako. アイヌの世界観一「ことば」から読む自然と宇宙 [The World-View of the Ainu]. Tokyo : Koudansha, 1994a. 278 p. (In Japanese).

Yamada Takako. Animals as the Intersection of Religion with Ecology : An Ainu Example // Circumpolar Religion and Ecology : An Anthropology of the North / ed. by T. Irimoto, T. Yamada. Tokyo : University of Tokyo Press, 1994b. P. 68-108.

Yamada Takako. Spirit Possession and Shamanism among the Ladakhi in Western Tibet // Shamans and Cultures / ed. by H. Mihály, K. Howard. Budapest: Akadémiai Kiadó, 1993. P. 214-222.

Yamada Takako. The Concept of Universe and Spiritual Beings Among Contemporary Yakut Shamans : The Revitalization of Animistic Belief and Shamanic Tradition // Circumpolar Animism and Shamanism. Hokkaido : Hokkaido University Press, 1997. P. 207-228.

Zola L. The Revival of Shamanism, Shamans, and Contemporary Art : The Case of the Sakha Republic (Yakutia) // Shaman. 2012. Vol. 20. No. 1-2. P. 157-174.

\section{References}

Balzer, M. M. (1993). Shamanism and the Politics of Culture: an Anthropological View of the 1992 International Conference on Shamanism, Yakutsk, the Sakha Republic, Shaman, Vol. 1, No. 2, pp. 71-96.

Balzer, M. M. (1996). Changing Images of the Shaman: Folklore and Politics in the Sakha Republic (Yakutia), Shaman, Vol. 4, No. 1-2, pp. 3-16.

Czaplicka, M. A. (1914). Aboriginal Siberia. 374p. Oxford, The Clarendon Press.

Gogolev A. I. (1994). Mifologicheskij mir Yakutov: Bozhestva i duhi-pokroviteli. [Mythological World of the Yakuts Deities and Spirits-Protectors]. 29 p. Yakutsk, Respublikanskij centr kul'tury' i iskusstva imeni A. E. Kulakovskogo.

Harva, U. (transl. by Katsuhiko Tanaka). (1989). Die Religiosen Vorstellungen der Altaischen Volker. Tokyo, Sanseido.

Jochelson, W. (1933). The Yakut. New York. (Anthropological Papers of the American Museum of Natural History. Vol. 33. Pt. 2).

Program and Abstracts of the $10^{\text {th }}$ Conference of the International Society for Shamanistic Research: Shamanhood and Its Art, Warsaw, 5-9 October 2011. (2011). 96 p. Warsaw.

Romanova, E. (1993). Ojunnara [Oyunnara]. In Ojunn: sbornik po yakutskomu shamanizmu (pp. 7-9). Yakutsk, Yakutskij institut yazy'ka, literatury' i istorii. (In Yakut).

Romanova, E. (1994). Yakutskij prazdnik Y'sy'ah: istoki i predstavleniya [Yakut Festival Ysyakh]. 159 p. Novosibirsk, Nauka.

Rozwadowski, A. (2014). In Search of Shamanic Themes in Eastern Siberian Rock Art (Yakutis/ Sakha Republic), Shaman, Vol. 22, No. 1-2, pp. 96-118. 
Suzdalov-Sappalaj, I. A. (1993). Ajj Ojuuna [Ayii Oyuuna]. In Ojunn: sbornik po yakutskomu shamanizmu (pp. 47-50). Yakutsk, Yakutskij institut yazy'ka, literatury' i istorii. (In Yakut).

Yamada, Takako. (1993). Spirit Possession and Shamanism among the Ladakhi in Western Tibet. In Mihály, H. \& Howard, K. (Eds.). Shamans and Cultures (pp. 214-222). Budapest, Akadémiai Kiadó.

Yamada, Takako. (1994a). アイヌの世界観一「ことば」から読む自然と宇宙［The World-View of the Ainu]. 278 p. Tokyo, Koudansha. (In Japanese).

Yamada, Takako. (1994b). Animals as the Intersection of Religion with Ecology: An Ainu Example. In Irimoto, T. \& Yamada T. (Eds.). Circumpolar Religion and Ecology: An Anthropology of the North (pp. 68-108). Tokyo, University of Tokyo Press.

Yamada, Takako. (1997). The Concept of Universe and Spiritual Beings Among Contemporary Yakut Shamans: The Revitalization of Animistic Belief and Shamanic Tradition. In Circumpolar Animism and Shamanism (pp. 207-228). Hokkaido, Hokkaido University Press.

Zola, L. (2012). The Revival of Shamanism, Shamans, and Contemporary Art: The Case of the Sakha Republic (Yakutia), Shaman, Vol. 20, No. 1-2, pp. 157-174.

Translated by Ekaterina Chiglintseva and Elena Glavatskaya

The article was submitted on 03.05.2015

Такако Ямада,
доктор биологических наук,
профессор-эмеритус,
Университет г. Киото, Япония
yamada.takako.78a@st.kyoto-u.ac.jp
Takako Yamada, Dr. Emeritus Professor, Kyoto University, Japan yamada.takako.78a@st.kyoto-u.ac.jp 